\title{
Erratum to: Spontaneous Entrainment of Running Cadence to Music Tempo
}

Edith Van Dyck ${ }^{1 *}$, Bart Moens ${ }^{1}$, Jeska Buhmann ${ }^{1}$, Michiel Demey ${ }^{1}$, Esther Coorevits ${ }^{1}$, Simone Dalla Bella ${ }^{2}$ and Marc Leman ${ }^{1}$

Unfortunately, the original version of this article [1] contained an error. In the captions for both Fig. 1 and Fig. 4, the sentence "Data presented is mean $\pm \mathrm{SE} "$ should be replaced by "Data presented is mean $\pm 95 \%$ CI" as presented below:

\footnotetext{
Author details

'IPEM, Department of Arts, Music and Theatre Sciences, Ghent University, Technicum Blok 2, Sint-Pietersnieuwstraat 41, Ghent, Belgium. ${ }^{2}$ EuroMov, Movement 2 Health Laboratory (M2H), University of Montpellier, 700 Avenue du Pic Saint Loup, Montpellier, France.
}

Received: 26 August 2015 Accepted: 26 August 2015

Published online: 11 September 2015

\section{Reference}

1. Van Dyck E, Moens B, Buhmann J, Demey M, Coorevits E, Dalla Bella S, et al. Spontaneous Entrainment of Running Cadence to Music Tempo. Sports Med Open. 2015;2:15.

\footnotetext{
* Correspondence: edith.vandyck@ugent.be

'IPEM, Department of Arts, Music and Theatre Sciences, Ghent University, Technicum Blok 2, Sint-Pietersnieuwstraat 41, Ghent, Belgium

Full list of author information is available at the end of the article
}

Submit your manuscript to a SpringerOpen ${ }^{\odot}$ journal and benefit from:

- Convenient online submission

- Rigorous peer review

- Immediate publication on acceptance

- Open access: articles freely available online

- High visibility within the field

- Retaining the copyright to your article

Submit your next manuscript at $>$ springeropen.com

\section{黑 Springer}

(c) 2015 Van Dyck et al. Open Access This article is distributed under the terms of the Creative Commons Attribution 4.0 International License (http://creativecommons.org/licenses/by/4.0/), which permits unrestricted use, distribution, and reproduction in any medium, provided you give appropriate credit to the original author(s) and the source, provide a link to the Creative Commons license, and indicate if changes were made. 


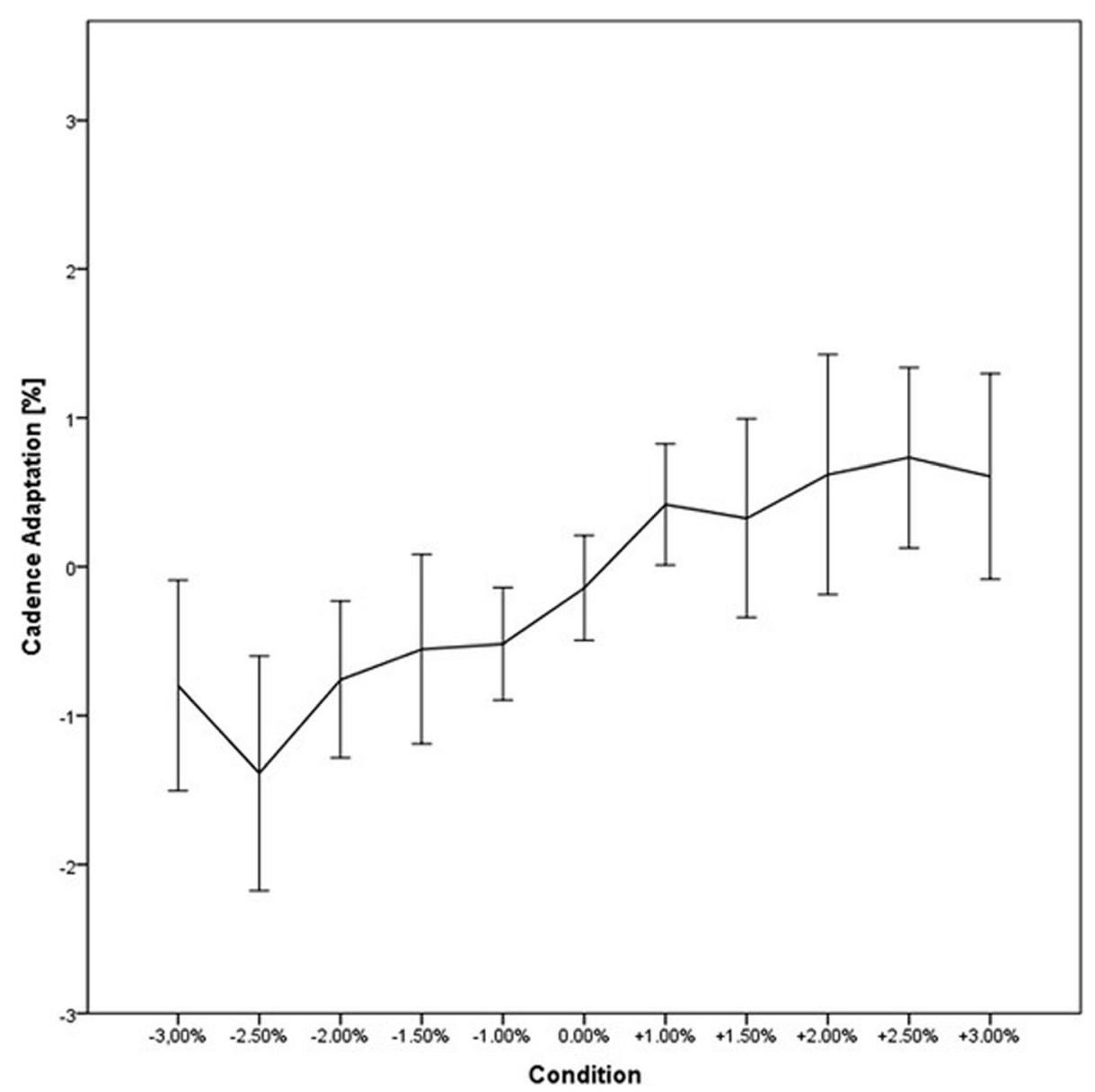

Fig. 1 Mean tempo and cadence adaptation for the different conditions. Data presented is mean $\pm 95 \% \mathrm{Cl}$ 


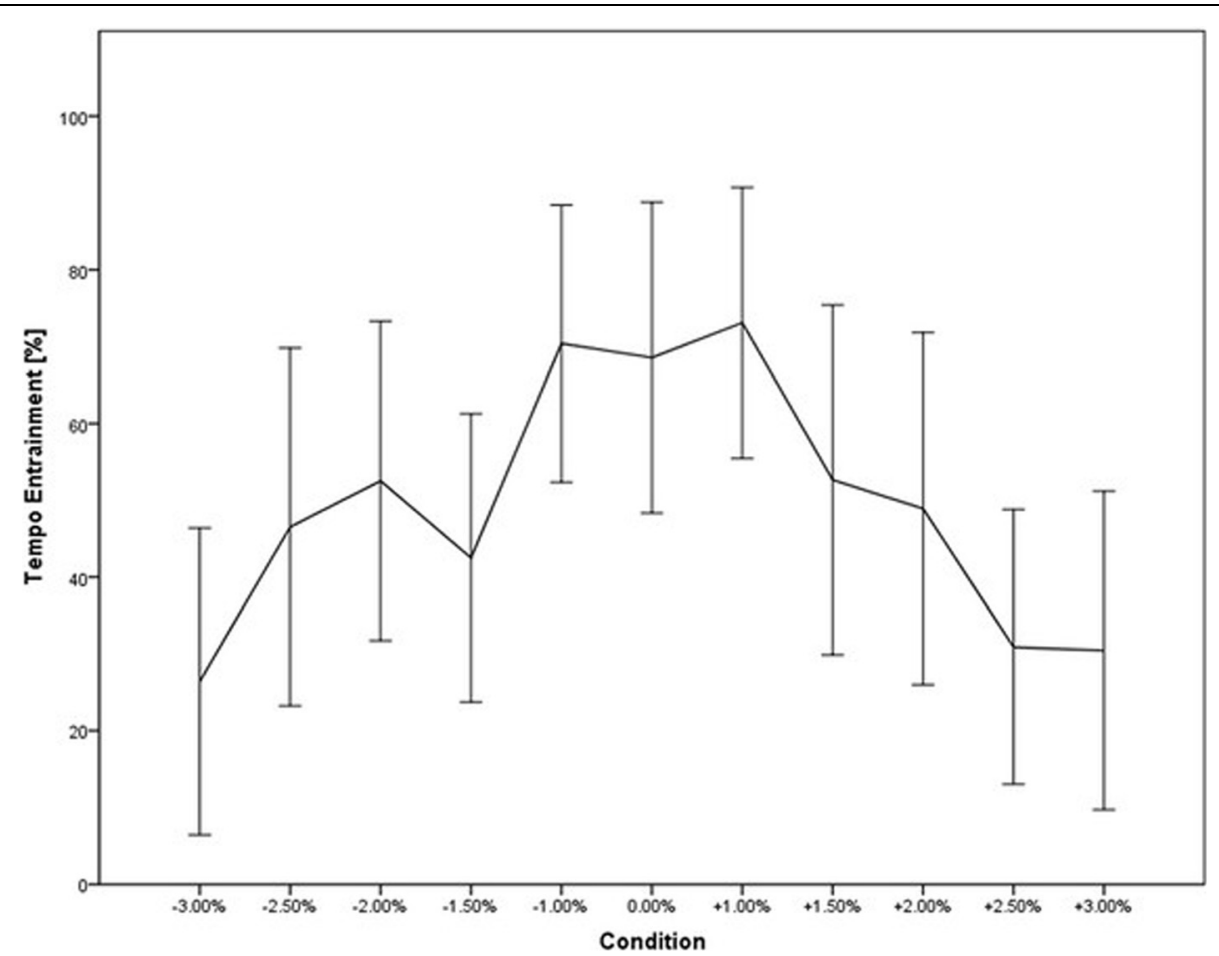

Fig. 4 Entrainment basin displaying mean tempo entrainment for the different conditions. Data presented is mean $\pm 95 \% \mathrm{Cl}$ 